Special Issue of the 6th International Congress \& Exhibition (APMAS2016), Maslak, Istanbul, Turkey, June 1-3, 2016

\title{
The Cathodic Electrolytic Plasma Hardening of Steel and Cast Iron Based Automotive Camshafts
}

\author{
A. DAYAnÇ ${ }^{a, *}$, B. KARACA ${ }^{a}$ And L.C. KumRUOĞLU ${ }^{b}$ \\ ${ }^{a}$ Estaş Eksantrik San. ve Tic A.Ş, Sivas-Turkey \\ ${ }^{b}$ University of Cumhuriyet, Engineering Faculty, Department of Metallurgy and Materials Eng., Sivas-Turkey \\ Cathodic electrolytic plasma hardening is a novel thermochemical surface modification and hardening process, \\ used to increase wear resistance and surface hardness of metallic components in a local area of interest. The heating \\ efficiency is related with the plasma nozzle design, applied current and electrolyte. The nozzle design is also a \\ critical factor for the hardening of complex shapes, such as gears and camshafts. In this work, lobes of camshafts, \\ fabricated from several cast iron and steel grades were hardened by cathodic electrolytic plasma hardening in \\ aqueous carbonate electrolyte, using a specific plasma nozzle. The camshafts were attached to CNC lathe for \\ turning them in the horizontal axis. In order to optimise heating and to achieve the ideal flowing and wetting by \\ the electrolyte of the lobe case, the ceramic ellipse-shaped nozzle outlet was designed. As a result of preliminary \\ studies, external surface of lobes was heated and subsequently quenched by electrolyte. The hardness of processed \\ surface was in the range of 50-60 HRc for the different camshafts. No distortion was observed on the surface of \\ lobes. Hardness depth was measured to be from $0.1 \mathrm{~mm}$ to $5 \mathrm{~mm}$ for several lobes.
}

DOI: 10.12693/APhysPolA.131.374

PACS/topics: 81.65.Lp, 82.45.Hk, 81.40.Pq

\section{Introduction}

Surface hardening is a process that includes a wide variety of techniques. It is used to improve the wear resistance of parts without affecting the softer, tough interior of the part. This combination of hard surface and resistance to breakage upon impact is useful in such parts, as a cam or ring gear, bearings or shafts and automotive components that must have a very hard surface to resist wear, along with a tough interior, to resist the impact that occurs during operation. Most surface treatments result in compressive residual stresses at the surface, that reduces the probability of crack initiation and helps to arrest crack propagation at the case-core interface [1].

Athodic electrolytic plasma hardening $(\mathrm{CEPH})$ can significantly enhance the functional properties of materials, even after a very short treatment period. This technique can provide high heating rate due to the large quantity of glow discharges. The hydrogen generated near the local area of metal surface and subsequent quenching result in the formation of multi-phase mixtures of $\mathrm{Fe}_{2-3} \mathrm{O}_{4}$, austenite, martensite, $(\mathrm{Fe})_{x} \mathrm{C}$ and nanocrystalline layer. The major advantage of the plasma electrolytic hardening is shown to be hardened layer (max. $900 \mathrm{HV}$, min. $500 \mathrm{HV}$ ) of the substrates, consisting of martensitic phase of approximately $7 \mathrm{~mm}$ thick, after a very short treatment of $0.5 \mathrm{~min}$. [2,3].

The more common methods currently used to harden the surface of steels include flame and induction hardening. However, each of these methods has shortcomings

*corresponding author; e-mail: ayhan.dayanc@estas.com.tr that can prevent its use in some applications. For example, the disadvantages of flame hardening include the possibility of part distortion, while induction hardening requires close coupling between the part and the coil (especially when using high frequencies), which must be precisely maintained [1]. Furthermore, induction hardening gives a homogenous microstructure with good wear resistance, but would be expensive to implement on a cylinder head production line due to the slow speed of the process [4].

Localized heating and quenching, without any chemical modification of the surface can be achieved by $\mathrm{CEPH}$ of steel and cast iron. CEPH hardening also gives a homogenous hardened martenstic microstructure with good wear resistance [3]. Camshafts are generally made of nodular cast iron, grey cast iron, chilled grey cast iron and steel. Camshaft lobes work under complicated conditions of mechanical load, and wear during the operation. The contact surfaces of the cam and the follower are usually surface hardened. The hardening may be due to phase transformation or precipitation processes, occurring on the material during heat treatment or thermochemical treatment [5].

CEPH process has been used to harden several ferrous materials, such as medium carbon steel and tool steel. Many studies were performed on the flat samples. However, there is no study about the directly hardening of camshafts. Even though a wide range of materials have been studied using the CEPH, there are no published studies dealing with the problem of camshaft hardening and wear resistance. The main objective of this paper is to study and experimentally (pilot scale) quantify the surface hardening of several types of original camshafts and their bearings. 


\section{Materials and experimental method}

Different types of camshafts, made of nodular cast iron (NCI), gray cast iron (GCI) and C45 steel, were machined and grinded to achieve final surface roughness. The photograph of camshafts is given in Fig. 1.

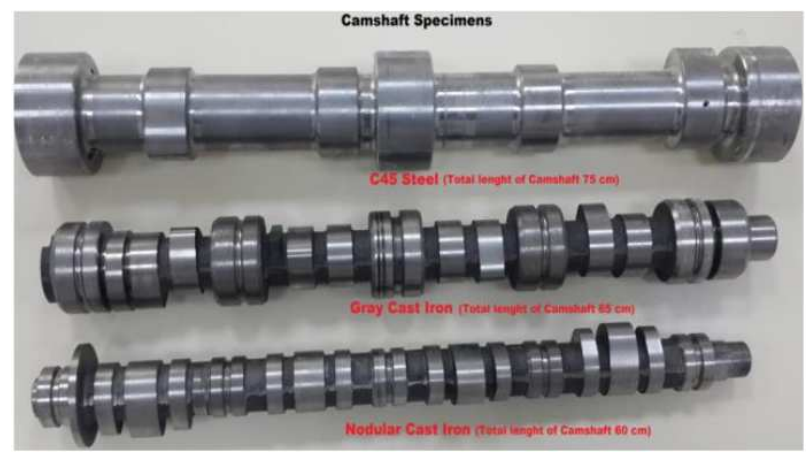

Fig. 1. Photo of camshafts before CEPH process.

CEPH was carried out on a specially designed and instrumented rig. The cathodic heating and camshaft position are shown in Fig. 2a and b, respectively. This rig consists of a RPM-controlled motor driver, plasma nozzle, electrolyte, electrolyte pump, PVC-based electrolyte container, thermocouples, electric connection clamps, polymer-based insulation bearings and a DC power supply. Prior to CEPH, the camshafts were fixed between two tailstocks. One of the tailstocks was made by PTFE and another of copper. PTFE side is inserted in the RPM controlled motor driver to rotate the camshafts. The copper tailstock is used to connect the cathode pincer. In this way both, the camshafts were rotated and the potential was applied.

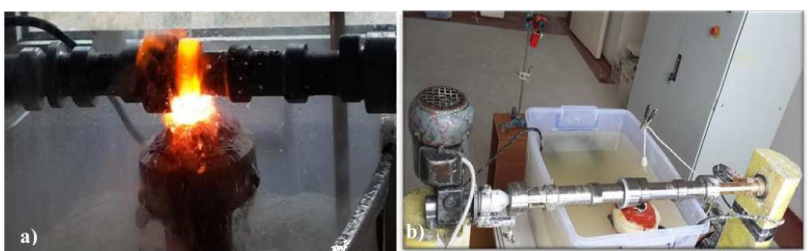

Fig. 2. CEPH process (a) plasma arc heating, (b) camshaft assembly.

An aqueous solution was prepared with 15 wt.\% of $\mathrm{Na}_{2} \mathrm{CO}_{3}$ and di-water. The conductivity of electrolyte was $90 \mathrm{mS}$ and the $\mathrm{pH}$ was 11 . The electrolyte temperature was varied between $55-60^{\circ} \mathrm{C}$. Electrolyte temperature was measured by plastic-covered thermocouple probe, using continuous measurement technique. The CEPH unit had a DC power supply with $800 \mathrm{~V}-500$ A power capacity. The CEPH process was performed under potential control. The camshafts were biased negatively and treated for 1.5 min for each camshaft lobe and 2 min for bearings, at the potentials varying from $250 \mathrm{~V}$ to $400 \mathrm{~V}$. The electrolyte was pumped from the container to the bottom surface of the camshaft lobes and bearings, then the potential was set automatically to fix the plasma envelope. Electrolyte flow was set to $8 \mathrm{l} / \mathrm{min}$ and adjusted by valve control. To prevent the melting on the sharpened edges and corners of cam lobes, the electrolyte was directed on the cam lobe surface in a small plasma spot area. Radius of plasma spot was smaller than the dimension of lobe surface. For each different size of lobes and bearings, different shape of nozzle was used, to achieve the control of heating area and of the flow of electrolyte. During the plasma heating the camshafts were rotated by rotating speed-controlled electric motor to heat cam lobes and than to subsequently quench them. The temperature of heated cams and bearings was measured by infrared thermometer, as shown in Fig. 3.

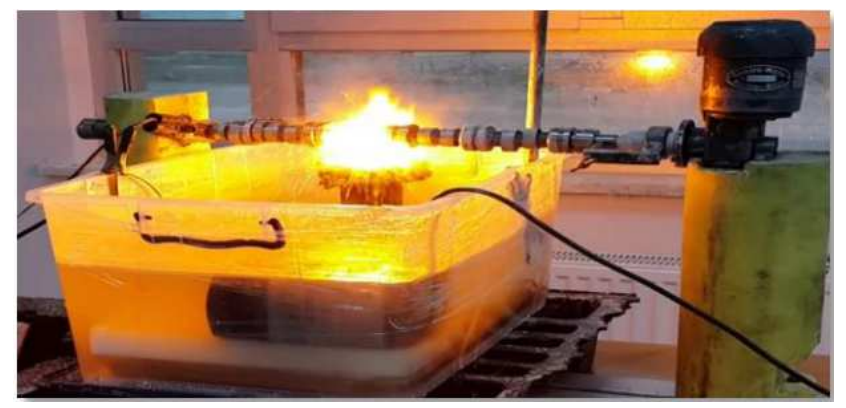

Fig. 3. Local heating of camshaft lobe by CEPH.

Infrared temperature measurement was continuously recorded. When surface of bearings or lobes had reached $750^{\circ} \mathrm{C}$, the DC power was switched off, to cut the energy, and camshafts were quenched by the same electrolyte which was used for heating. In addition a second quenching pump was used to make aggressive quenching. However, because of the different melting temperatures of steel, grey cast iron and nodular cast iron camshafts, different surface temperatures were set to prevent surface melting. For the grey and nodular cast iron the optimum surface temperature was $675^{\circ} \mathrm{C}$. Experiments show that below $675^{\circ} \mathrm{C}$, the hardened area was not homogeneous along the circumference of lobes and bearings. For the steel, the surface temperature was $750^{\circ} \mathrm{C}$. Similarly, below $750^{\circ} \mathrm{C}$, the hardened area was not homogeneous along the circumference of lobes and bearings.

The second problem consisted in not deep enough hardened layer. Lowering the DC potential from $400 \mathrm{~V}$ to $300 \mathrm{~V}$ has solved this problem. However, reducing the DC potential had caused the increase of the duration of hardening from $60 \mathrm{~s}$ to $80 \mathrm{~s}$. Another technical problem was in the shape of camshaft lobes. Lobes are generally designed as asymmetric shapes, consisting of base circle and nose. During heating of rotating lobes, for a fixed plasma nozzle, nose part of the lobe gets more energy because of plunging into the electrolyte. That is why nose parts may get hot rapidly and break the steadystate plasma envelope. This causes the melting of the edges of noses. 
This problem was overcame by changing the plasma nozzle system. Plasma nozzle was settled on a table moving up-down. When the nose part of lobe went down in the electrolyte, the moving table had adjusted the gap between nozzle and nose by following the route similar to nose route. Moving the plasma nozzle had stabilized the current density and plasma heating. After stabilizing the heating system all camshaft lobes and bearings were heated up to related temperature that was discussed before.

Later lobes and bearings were cut to study the microstructure and to measure the hardness depth and surface hardness on the cross-section. The hardness profiles of C45 steel (Fig. 4a), of nodular cast iron (Fig. 4b) and of grey cast iron (Fig. 4c) are presented here with with related macrostructure, produced by etching in $4 \% \mathrm{HNO}_{3}$.
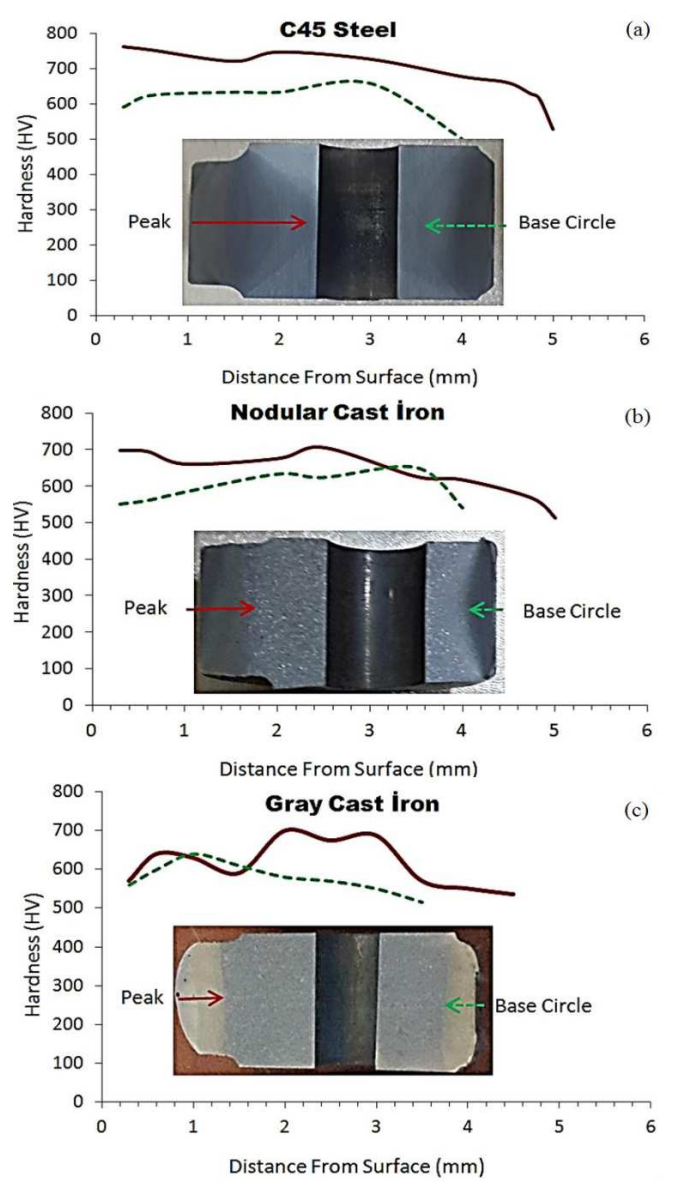

Fig. 4. Hardness profile of (a) C45, (b) NCI and (c) GCI and their macrostructures.

The hardness depth of CEPH was evaluated by micro hardness testing, from surface to centre of the base circle and of the peak of lobes. At low voltages, such as $300 \mathrm{~V}$, some slight increases of hardness was measured near the surface of the treated layer. The hardness depth was detected to be $1000 \mu \mathrm{m}$ beneath the surface. This is probably because of current fluctuations during the dis- charging and of inadequate heating. As the treatment voltage increased from $350 \mathrm{~V}$ to $400 \mathrm{~V}$, depending on the increase in austenising temperature and austenised depth of samples, the micro hardness and the depth of hardened zone had increased, due to high plasma discharge energy at the active surface and the very fast cooling rates. As shown in Fig. 4, a hardened layer of approximately $5 \mathrm{~mm}$ was achieved on C45 steel and on nodular cast iron without any defects. On the other hand, a $4 \mathrm{~mm}$ hardened layer was achieved on grey cast iron. During heating, the heating rate at the surface of the heated workpiece is always higher, compared to the heating rate of internal areas of the workpiece and particularly, compared to the heating rate at its core.

As can be seen, the CEPH has raised the hardness at the specimen surfaces to $650-750 \mathrm{HV}$. The hardness of the untreated specimens was assumed to be uniform, at 200-250 HV. Because of the asymmetric shape of cam lobes the hardness depth of peak (nose) was larger than that of the base circle for all lobes. However, this type of hardened layer may bring an unique advantage. Many automotive industries prefer deeper hardness on peak side of lobe due to the wear mechanism. Considering the camshaft working conditions, one can observe that, the nose side is exposed to wear loads, which may cause severe wear of material.

The normal microstructure of the GCI and NCI consists of a mixture of short graphite flakes and spheroids of graphite, as shown in Fig. 5. A ring of ferrite, giving the classic "bulls eye" structure, surrounds the nodular graphite. Many of the short graphite flakes are also surrounded by ferrite. The matrix primarily consists of a fine pearlite. An image from a section through the hardened surface of specimen plasma hardened to $5 \mathrm{~mm}$ is shown in Figs. 4 and 5. The needle-like structure of martensite is clearly visible (Fig. $5 \mathrm{a}-\mathrm{c}$ ) in a specimen showing the martensitic structure. The structure consists of the same graphitic structures but both, the pearlite and the ferrite phases have been transformed to martensite by the plasma hardening.

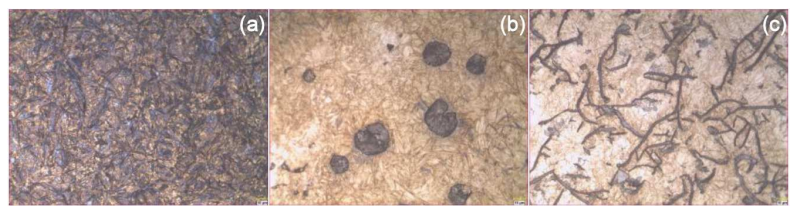

Fig. 5. A section through the plasma hardened surface of a $4 \mathrm{~mm}$ hardened specimen, showing the finer martensite for the C45 steel (a), fine martensite around the spheres of graphite for the NCI (b) and flake graphite for the GCI (c).

Figure 6a shows the SEM image of the martensitic microstructure of nose side of lobes made of C45 steel. The microhardness of this martensitic zone was $675-750 \mathrm{HV}$. Figure $6 \mathrm{~b}$ and $\mathrm{c}$ shows the SEM image of NCI and GCI lobes, taken from fully hardened nose side. In this area, 
dispersed graphite spheres and graphite flakes were observed in the fine martensitic matrix. For all cams, from the surface to the base metal, the hardness values decreased and the phase structure changed into a ferriticpearlitic matrix. In this zone hardness was measured to be 30-32 HRc.
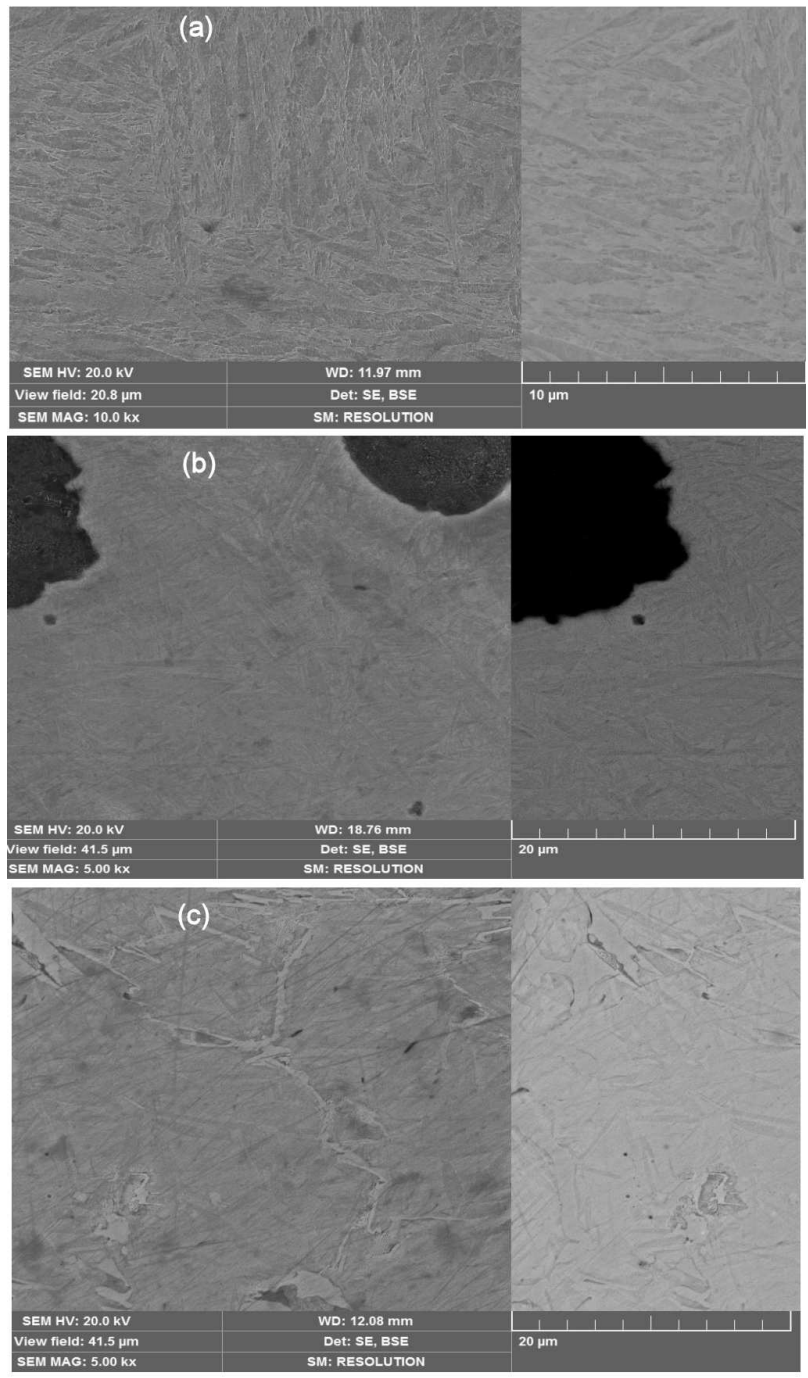

Fig. 6. SEM micrograph of longitudinal section of the cam lobes (martensitic nose side).

Dry sliding wear tests were performed using a ball-ondisk type of wear testing. The wear tests were carried out at the sliding speed of $0.1 \mathrm{~m} \mathrm{~s}^{-1}$, using applied load of $30 \mathrm{~N}$ for $100 \mathrm{~m}$ and $500 \mathrm{~m}$ distances. The wear test samples were taken from nose side of each tested part. The wear results have shown that wear resistance of modified samples had significantly increased and friction coefficient had decreased (Fig. 7).

It is expected that the hardened zone may provide a better wear resistance due to its high hardness. Figure 7 shows the variation of wear loss at $30 \mathrm{~N}$ applied normal load and at 100-500 $\mathrm{m}$ sliding distance for the treated

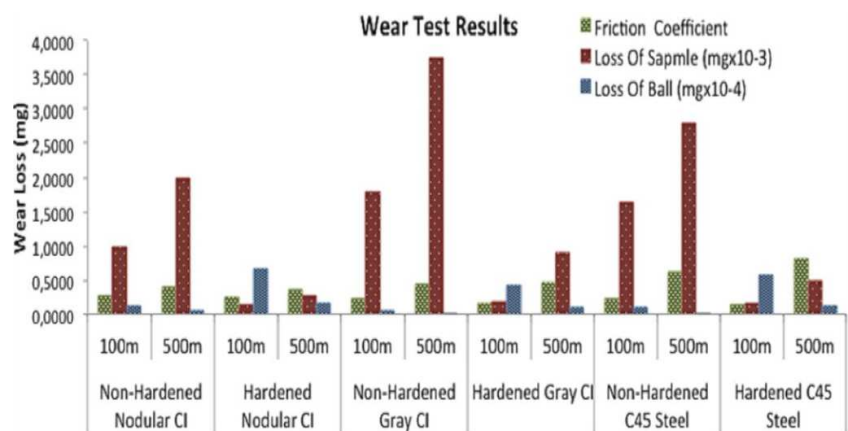

Fig. 7. Wear loss and friction coefficient for C45, NCI and GCI specimens, for different applied loads and sliding distances.

specimen. It can be seen that the wear loss does show a remarkable decrease, for NCI and GCI. The wear resistance after plasma hardening is much greater, compared to that of the untreated cam lobes under the same load.

The best wear resistant was achieved for the NCI, which was heated for $60 \mathrm{~s}$ and subsequently quenched. The wear resistance of GCI is lower than that of the NCI. This decrease can be explained by the overheating and surface roughening. Examination of the worn surfaces has revealed that under sliding against the AISI 52100 steel counter face, wear of the untreated austenitic C45 steel occurred in a severe mode characterised by surface plastic deformation, shearing, material transfer and abrasion, while the CEPH treated surfaces were worn in a mild mode, characterised by micro-abrasion and surface polishing.

In addition to discussed above wear mechanism, a close study of the worn surfaces of the CPEH treated samples has suggested that there is deformation and fatigueinduced scaling of the oxide layer, formed on the surface of the treated sample. Moderate adhesive/abrasive wear mechanisms also have been reported for plasma electrolytic treatment performed at $250 \mathrm{~V}$ [6]. Considering the cast irons, lamellar graphitic cast structure, containing long cementite with sharp tips and edges, suffers from micro cracking tendency, while a combination of hardness and strength of the cementite phase in the soft and ductile ferrite offers load-bearing characteristics.

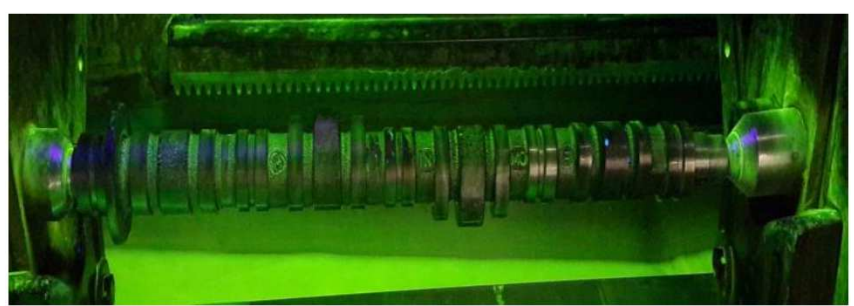

Fig. 8. The penetrant testing experiment.

Graphite flakes offer lubricating characteristics in general in conditions favouring smearing of the phase on the contacting surfaces. Conditions allowing other micro 
constituents to play their positive roles, like having loadbearing characteristics, accommodating various phases and providing smearing caused by the formation of lubricating film, also offer improved wear performance [7]. In order to reveal the micro cracks that originated form rapid surface heating and subsequent quenching, in the $\mathrm{CEPH}$ treated cam lobes, liquid penetrant testing was performed. The results have show that there were no crack on the hardened surfaces. The penetrant testing experiment is shown in Fig. 8.

\section{Conclusions}

Cathodic electrolytic plasma hardening is performed by means of electrical discharge in the plasma layer between the camshaft lobe surface and the electrolytic electrode, which flows from the perforated hole on the lobe subsurface. The electrolyte is used for heating and cooling of the lobe surface. Cathodic electrolytic plasma hardening allows a wide variation of the heating and cooling rates $\left(50-400{ }^{\circ} \mathrm{C} / \mathrm{s}\right)$ and producing a treated layer with thickness of 0.1 to $10 \mathrm{~mm}$. A hardened layer with the depth of $6 \mathrm{~mm}$ is formed at the surface during the treatment at $675-750{ }^{\circ} \mathrm{C}$ for a few minutes in a $15 \mathrm{wt} . \%$ sodium carbonate solution.

$\mathrm{CEPH}$ is one of the innovative technologies that have been investigated extensively on industrial level. After optimization of electroytic plasma technology, surface of C45 steel, gray CI and nodular CI camshafts have been modified. While the value of micro-hardness of the samples was found to be approximately $180 \mathrm{HV}$ without $\mathrm{CEPH}$, this value was raised up to $780 \mathrm{HV}$ within very short time from 30 to 120 seconds after the treatment. The hardened layer dept may change by varying the heating rate and chamshaft rotation rate. The value of macro-hardness of the surface of the samples was increased from 15 HRc to approximately 60 HRc. Dry sliding wear tests were performed using a ball-on-disk type wear testing. The wear results have shown that wear resistance of modified samples increased 5 and 6 times, for the steel and cast iron camshafts. Friction coefficient has decreased nearly two or three times. The application of CEPH process was successfully applied to the original, industrially used automotive camshafts.
CEPH was also compared with another common hardening technology which is called induction hardening. Compared with the induction hardening, the CEPH has some advantages, such as economical start-up investment cost, low cost consumable materials, controllable hardened layer depth, controlled by voltage and treatment duration. Novel plasma nozzle design that controls the gap between lobe surface and electrolyte provides a successful hardening process, by preventing the local surface melting. The best result was achieved on the NCI samples that have unique microstructure that consist of nodular graphite and hard martensitic matrix.

\section{Acknowledgments}

This work has been supported by the Cumhuriyet University (Cubap-) project Nr. M582.

\section{References}

[1] S. Lampman, Introduction to Surface Hardening of Steels, Heat Treating, Vol. 4, ASM Handbook, ASM International, 1991, p. 259.

[2] T. Mizuno, Japan. J. Appl. Phys. 44, 396 (2005).

[3] L.C. Kumruoglu, MTAEC9 47, 307 (2013).

[4] T. Slatter, Wear 267, 797 (2009).

[5] J. Michalski, Wear 240, 168 (2000).

[6] F. Mahzoon, Iran. J. Mater. Sci. Eng. 10, 22 (2013).

[7] S. Kumar, A. Bhattacharyya, D. Kumar Mondala, K. Biswas, J. Maity, Wear 270, 413 (2011). 